\title{
EFEKTIFITAS MOLUKISIDA MINYAK SIRIH SIRIH DAN LEMONGGRAS TERHADAP HAMA KEONG MAS PADA TANAMAN PADI
}

\author{
Herwita Idris* dan Nurmansyah \\ Kebun Percobaan Balittro Laing Solok, \\ Jln. Kapten Bahar Hamid, \\ *Email: herwitaidris@gmail.com)
}

\begin{abstract}
ABSTRAK
Minat masyarakat Indonesia dalam menggunakan pestisida nabati terus meningkat sehingga perkembangan penelitian mengenai pestisida nabati sangat prospektif, walaupun daya kerja pestisida nabati agak lambat dan memerlukan frekuensi pemberian lebih banyak, namun efeknya lebih baik bagi lingkungan, karena mudah terurai di alam. Untuk itu telah dilakukan penelitian efektifitas molukisida nabati berbahan minyak sirih sirihan dan lemongrass terhadap hama keong mas tanaman padi. Penelitian disusun dalam bentuk Rancangan Acak Kelompok dengan 7 perlakuan dan 8 ulangan masing-masing perlakuan terdiri dari 15 ekor keong mas dengan berat relatif sama. Perlakuan tersebut adalah 1). minyak sirih-sirihan kosentrasi 165 ppm, 2). minyak sirih-sirihan kosentrasi 325 ppm, 3). minyak sirih-sirihan kosentrasi 625 ppm, 4). minyak lemongrass kosentrasi 165 ppm 5). minyak lemongrass kosentrasi 325 ppm, 6). minyak lemongrass kosentrasi 625 ppm dan 7). Sebagai pembanding minyak kayu manis kosentrasi 625 ppm, dengan lama waktu perendaman 24 jam. Hasil penelitian menunjukkan bahwa molukisida nabati minyak sirih sirihan pada kosentrasi 325 ppm mampu menghambat makan keong mas dan menyebabkan kematian mencapai $100 \%$, dan juga dapat meningkatkan pertumbuhan vegetatif dari tanaman padi. Dari hasil penelitian ini diharapkan dengan menggunakan molukisida nabati, tidak saja dapat mengendalikan serangan hama keong mas akan tetapi juga dapat meningkatkan produksi dari tanaman padi, serta menambah nilai tanaman liar menjadi tanaman yang bernilai ekonomis.
\end{abstract}

Kata kunci: Keong mas, lemonggras, minyak sirih-sirihan, nilai ekonomis, tanaman liar

\section{ABSTRACT}

The interest of Indonesian people in using plant pesticides continues to increase so that the development of research on plant pesticides is very prospective, although the working power of plant pesticides is rather slow and requires more frequent administration intervals, but the effect is better for the environment. Besides botanical pesticides also have the advantage of being easily decomposed. For this reason, tests have been carried out on botanical molucicide made from spiked piper oil and lemongrass against golden apple snail pest with a randomized block design that is 7 treatments with 8 replications each treatment of 15 golden apple snails with the same relative weight. The treatment is 1). spiked piper oil concentration of 165 ppm, 2). spiked piper oil concentration 325 ppm, 3). spiked piper oil, concentration 625 ppm, 4). concentrated lemongrass oil 165 ppm 5). 
concentration of 325 ppm lemongrass oil, 6). Lemongrass oil concentration of 625 ppm and 7). As a comparison of cinnamon oil concentration of $625 \mathrm{ppm}$, with a soaking time of 24 hours. The results showed that botanical spiked piper oil molucides at a concentration of 325 ppm were able to inhibit the eating of golden apple snails and cause mortality to reach 100\%, and also could increase the vegetative growth of rice plants. golden apple snail pests, but can also increase production from rice plants, and increase the value of wild plants into economically valuable plants.

Keywords: golden apple snail, lemonggras, spiked piper oil, economic value, wild plants

\section{PENDAHULUAN}

Pemanfaatan pestisida nabati di Indonesia saat ini cukup prospektif, dan kemauan masyarakat untuk menggunakannya sudah mulai meningkat, walaupun mempunyai daya kerja lambat, frekuensi aplikasi lebih sering, karena mudah terurai, namun efeknya lebih baik bagi lingkungan, serta teknologinya sudah berkembang dengan lebih baik.

Sirih-sirihan (Piper aduncum), merupakan tumbuhan liar berbentuk pohon kecil dengan tinggi 3-6 $\mathrm{m}$ daun tersebar berbentuk ovatus, elips sampai oblongus dengan panjang 8-17 cm, lebar 3-8 cm dengan tulang daun melengkung. Tumbuh ini termasuk famili Piperaceae, mengandung minyak atsiri dengan rendemen 0,214-0,225\% dari bahan basah, bila bahan dilayukan rendemen dapat mencapai $0,86 \%$ dari bahan siap suling (Nurmansyah, 2012). Kandungan utama minyak atsiri sirih-sirihan adalah phenylpropanoid dilapiole $(32,9-61,8 \%)$, monoterpenoids piperiton $(2,2-13,5 \%)$, 1,8-cineole dan $\beta$-caryophyllene 4,05,3\% (Cicció, et al., 1997). Disamping itu juga merupakan tanaman obat yang mempunyai kandungan kimia utama yaitu saponin, flavonoid dan polifenol, (Sudrajat et al., 2011). Dari hasil penelitian (Jamal,Y dkk, 2003) minyak atsiri dari tanaman sirih-sirihan tidak saja didapat dari daun akan tetapi juga ditemukan pada buahnya yang terlebih dahulu dijadikan serbuk kering yang mengandung sekitar 1,55\% minyak atsiri. Minyak atsiri yang bersal dari buah sirih-sirihan ini mengandung 63 komponen kimia yang terdiri dari 5,74\% monoterpena, 2,84 monoterpena alkohol, $14,61 \%$ seskiterpena, $0,18 \%$ seskiterpena alkohol, 56,28\% fenil propanoid dan $20,35 \%$, dari 63 komponen kimia yang menyusun minyak buah sirih-sirihan, 10 diantaranya adalah komponen utama yaitu $\gamma$-terpinena, 4-metil-1-(1-metiletil)3-sikloheksen-lol, tetradekana, isokariofilena, $\alpha$-kariofilena, (1S-cis) 1,2,3,5,6,8a-heksahidro-4,7-dimetil-1-(1metiletil) naftalena (tipe 2), miristisin (tipe 2) dan apiol serta satu komponen yang tidak teridentifikasi.

Minyak atsiri dari Lemonggras (Cymbopogon flexuosus) sejenis minyak serai dapur dengan kandungan utama adalah sitral berkisar $75-88 \%$, dengan rendemen minyak dari bahan segar $0,4 \%$. Tanaman ini dapat dipanen setiap 3-4 bulan dengan potensi produksi daun segar 65 ton/ha/tahun, minyak setara dengan $260 \mathrm{~kg}$ minyak $\mathrm{Ha}^{-1}$ tahun $^{-1}$ (Mauludi, L dan A. Asman, 2004).

Keong mas (Pomacea canaliculata, Lamarck: Ampullariidae) adalah sejenis Molusca yang berasal dari Amerika Selatan, mempunyai siklus hidup pendek, dengan tingkat keperidian yang tinggi serta beradaptasi sangat baik dengan lingkungan, sehingga mampu berproduksi dengan cepat serta cosmopolitan, yang memiliki ketahanan tubuh yang relatif kuat dan fertilitas yang tinggi, (Min and Yan, 2006; Putro, 2011). Biasa menyerang tanaman padi dari umur 15 hari setelah tanam dan terlihat diseluruh pertanaman padi di Asia Tenggara, (Prabhakaran, et al., 2017). Pada padi yang ditanam langsung (tabela) dapat terserang sampai umur 30 hari setelah tanam. Hama ini memakan 
pangkal bibit padi muda sampai seluruh tanaman hanya dalam waktu satu malam saja, dengan intensitas serangan13,2 96,5\% (Pitojo, 1996). Keong mas tidak saja merusak tanaman padi akan tetapi juga merupakan inang dari cacing parasit yang menyebabkan penyakit Schistosomiasis (Mwonga, KB., et al, 2016) Menurut Bunga, JA dkk, 2016 tingkat kerusakan bibit padi juga dipengaruhi oleh ukuran dari keong mas yang menyerang, semakin besar keong mas maka kerusakan yang ditimbulkan akan lebih parah, Pada tahun 2007 luas serangan keong mas di Indonesia mencapai 22.110 ha. Pada tahun 2014 produksi gabah kering giling terjadi penerunan dari tahun 2013 sebesar $0,63 \%$ salah satu penyebabnya adalah hama keong mas (Dirjen Perlintan, 2008 dan BPS, 2014).

Idris dan Nurmansyah (2018), melaporkan bahwa minyak kayu manis dosis 625 ppm dan waktu perendaman 24 jam sangat efektif mengendalikan hama keong mas ini dengan mortalitas $100 \%$. Berdasarkan hal diatas perlu diuji efektifitas minyak sirih-sirihan dan lemonggras kosentrasi 165 ppm, 325 ppm 625 ppm dengan waktu perendaman 24 jam dengan pembanding minyak kayu manis yang merupakan hasil yang terbaik dari penelitian sebelumnya. Sehingga didapat jenis pestisida nabati dan cara pengendalian hama keong mas yang terbaik.

\section{BAHAN DAN METODA}

Penelitian dilaksanakan dari bulan April 2019 sampai dengan bulan Desember 2019. Di Laboratorium Parasitologi Kebun Percobaan Balittro Laing Solok.

Dalam penelitian ini bahan yang digunakan yaitu minyak sirih sirih, minyak lemongrass, minyak kayu manis, bahan pengemulsi dan bahan pembasah. Sedangkan alat yang digunakan ember plastik berukuran 101 .
Penelitian ini menggunakan rancangan acak kelompok yaitu 7 perlakuan serta 8 ulangan masing-masing 15 ekor keong mas dengan berat relative sama. Perlakuan tersebut adalah 1). minyak sirih-sirihan kosentrasi 165 ppm, 2). minyak sirih-sirihan kosentrasi 325 ppm, 3). minyak sirih-sirihan kosentrasi 625 ppm, 4). minyak lemongrass kosentrasi 165 ppm 5). minyak lemongrass kosentrasi 325 ppm, 6). minyak lemongrass kosentrasi $625 \mathrm{ppm}$ dan 7). Sebagai pembanding minyak kayu manis kosentrasi 625 ppm, dengan lama waktu perendaman 24 jam.

\section{Prosedur kerja pengujian:}

\section{a. Penyulingan Bahan}

Bahan baku yang digunakan adalah daun dan ranting tanaman sirih- sirihan (P. aduncum) yang merupakan tumbuhan liar di daerah Kota Solok. Bahan yang diambil, kemudian dikering anginkan selama 7 hari dan setiap hari harus dibalik supaya keringnya merata. Sedangkan bahan lemongrass diambil dari Kebun Percobaan Balittro Laing Solok, juga dikeringkan secara pelayuan selama 2 hari di Rumah Kaca. Selanjutnya dilakukan penyulingan dilaboratotium Kebun Percobaan Balittro Laing Solok dengan metoda kukus. Penyulingan dilakukan selama 3 jam.

\section{b. Pembuatan Formulasi}

Minyak sebagai bahan baku diambil sesuai kosentrasi , kemudian ditambah dengan pengemulsi serta pelarut. Setelah itu di campur dan diaduk menggunakan stirer sampai homogen selama 20 menit .

\section{c. Pengujian Molukisida Nabati}

Keong mas dicari dari sawah yang berada di Kota Solok, kemudian diadaptasikan selama 1 hari, selanjutnya direndam dalam ember berdiameter 25 $\mathrm{cm}$ dengan tinggi $30 \mathrm{~cm}$, sebanyak 15 ekor ember ${ }^{-1}$ dengan air yang telah diberi perlakuan moluskisida nabati sesuai 
perlakuan Perendaman dilakukan selama 24 jam, setelah itu keong mas dipindahkan kedalam ember yang telah berisi air bersih sebanyak 51 , diberi makan dengan daun keladi yang sebelumnya sudah ditimbang, setelah itu dilakukan pengamatan sampai 48 jam dengan parameter pengamatan yaitu mortalitas keong mas serta persentase hambat makan dari keong mas dengan menggunakan rumus Prijono, 2005:

$P M=\frac{(\mathrm{Bk}-\mathrm{Bp})}{(\mathrm{Bk}+\mathrm{Bp})} \times 100 \%$

$\mathrm{PM}=$ Penghambatan makan

$\mathrm{Bk}=$ Berat daun kontrol yang dimakan

Bp = Berat daun perlakuan yang dimakan

Hasil yang didapat diolah secara statistik, apabila terdapat perbedaan yang siknifikan maka dilanjutkan dengan uji jarak berganda, dengan menggunakan program Sirichai versi 6,0.

\section{HASIL DAN PEMBAHASAN}

Dari hasil penelitian menunjukkan pemberian molukisida nabati mempengaruhi selera makan dari keong mas, terbukti dengan adanya hambat makan dari keong mas. Hambat makan tertinggi terdapat pada perlakuan MS 625 (minyak sirih-sirihan kosentrasi 625 ppm) sebesar $86,19 \%$, berbeda nyata dengan perlakuan ML 625 (minyak lemonggras kosentrasi $625 \mathrm{ppm}$ ) dan terendah perlakuan ML 165 dengan tingkat kosentrasi 165 ppm lebih lengkap (Tabel 1).

Dari tabel 1 juga dapat dilihat selain jenis bahan yang digunakan tingkat kosentrasi (kepekatan) molukisida nabati juga berpengaruh terhadap hambat makan, dimana hambat makan terkecil terdapat pada perlakuan ML 165 sebesar $74,7 \%$, hal ini sesuai dengan yang dilaporkan oleh (Yunidawati., dkk 2011), yaitu pada hari kesembilan jumlah tanaman padi yang terserang lebih sedikit dengan menggunakan ekstraks pinang 40 cc $\mathrm{L}^{-1}$ air dibandingkan dengan menggunakan ekstraks pinang $20 \mathrm{cc} \mathrm{l}^{-1}$ air $(2,35 \%)$.

Tabel 1. Hambat Makan Keong Mas Pengaruh Pemberian Molukisida Minyak Sirihsirih, Lemonggras dan kayu manis

\begin{tabular}{|c|c|c|c|}
\hline Perlakuan & \multicolumn{3}{|c|}{ \% Hambat Makan } \\
\hline MS $165 \mathrm{ppm}$ & $77,05 d$ & \pm & 0,73 \\
\hline MS 325 ppm & $79,7 \mathrm{c}$ & \pm & 0,39 \\
\hline MS 625 ppm & 86,9 a & \pm & 2,09 \\
\hline ML165 ppm & $74,7 \mathrm{e}$ & \pm & 0,39 \\
\hline ML $325 \mathrm{ppm}$ & $77,08 \mathrm{~d}$ & \pm & 0,05 \\
\hline ML $625 \mathrm{ppm}$ & $82,48 \mathrm{~b}$ & \pm & 0,73 \\
\hline MK 625 ppm & $81,3 \mathrm{bc}$ & \pm & 3,42 \\
\hline KK (\%) & 11,42 & & \\
\hline
\end{tabular}

Keterangan: Angka yang diikuti huruf kecil yang tidak berbeda nyata taraf uji $5 \%$ DMNRT.

MS 165 ppm rih-sirih $165 \mathrm{ppm}$

MS 325 ppm rih-sirih 325 ppm

MS 625 ppm rih-sirih 625 ppm

ML165 ppm emonggras $165 \mathrm{ppm}$

ML 325 pmm emonggras $325 \mathrm{ppm}$

ML $625 \mathrm{ppm}$ emonggras $625 \mathrm{ppm}$

MK 625 ppm ayu manis $625 \mathrm{ppm}$

Molukisida nabati tidak saja berpengaruh pada selera makan dari hama Keong mas, akan tetapi juga dapat mengganggu proses biologis dan menurunkan daya tetas telur, terjadi pada jenis siput Monacha obstructa (Hygromiidae; Stylommatophora), dengan molukisida yang mengandung azadirachtin $(0,03 \%)$ (Shoaib MA., et al. 2010).

Daya hambat makan juga akan mempengaruhi angka mortalitas dari Keong mas, dimana daya hambat makan yang tinggi akan menyebabkan mortalitas yang tinggi. Pemakaian minyak sirih-sirihan sangat efektif untuk pengendalian Keong mas, ini terbukti dengan angka mortalitas yang didapat yaitu pada pemakaian minyak sirih- 
sirihan $325 \mathrm{ppm}$ telah dapat menyebabkan mortalitas 100\% (Tabel 2).

Tabel 2. Mortalitas Keong mas dengan pengendalian molukisida nabati 48 jam setelah aplikasi

\begin{tabular}{|c|c|c|c|}
\hline Perlakuan & $\begin{array}{c}\text { Populasi } \\
\text { awal }\end{array}$ & Mort & alitas \\
\hline $\begin{array}{l}\text { MS } 165 \\
\text { ppm }\end{array}$ & 15 & $97,67 \mathrm{a}$ & $\pm 4,97$ \\
\hline $\begin{array}{l}\text { MS } 325 \\
\text { ppm }\end{array}$ & 15 & $100,0 \mathrm{a}$ & $\pm 0,00$ \\
\hline $\begin{array}{l}\text { MS } 625 \\
\text { ppm }\end{array}$ & 15 & $100,00 \mathrm{a}$ & $\pm 0,00$ \\
\hline $\begin{array}{l}\text { ML165 } \\
\text { ppm }\end{array}$ & 15 & $49,79 \mathrm{~b}$ & \pm 1.40 \\
\hline $\begin{array}{l}\text { ML } 325 \\
\text { ppm }\end{array}$ & 15 & $48,47 \mathrm{~b}$ & $\pm 13,01$ \\
\hline $\begin{array}{l}\text { ML } 625 \\
\text { ppm }\end{array}$ & 15 & $99,38 \mathrm{a}$ & $\pm 0,80$ \\
\hline $\begin{array}{l}\text { MK } 625 \\
\text { ppm }\end{array}$ & 15 & $98,00 \mathrm{a}$ & \pm 3.40 \\
\hline KK $(\%)$ & & 12,17 & \\
\hline
\end{tabular}

Keterangan:

- Angka yang diikuti huruf kecil yang tidak berbeda nyata taraf uji 5\% DMNRT.

- Perlakuan sama dengan tabel 1

Dari hasil pengamatan ternyata semakin lama waktu aplikasi maka semakin tinggi angka mortalitas keong mas Pada pengamatan setelah 48 jam aplikasi ternyata pemakaian molukisida minyak lemonggrass 165 dan 325 ppm angka mortalitasnya masih rendah dibandingkan dengan perlakuan lainnya (Gambar 1). Selanjutnya menurut (Bunga.JA dkk, 2016) kedalam air juga mempengaruhi mobilitas dari keong mas serta mempengaruhi juvenil dari imago. Dari hasil penelitian juga dapat dilaporkan bahwa molukisida minyak sirih sirihan dan lemongrass ternyata menyebabkan keong mas tidak dapat bertelur kecuali pada kontrol (tanpa perlakuan).

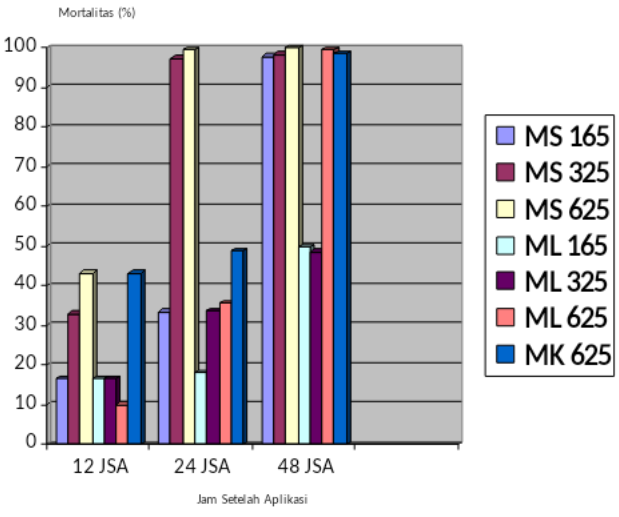

Gambar 1. Angka Mortalitas Keong Mas 12, 24 dan 48 jam setelah Aplikasi

Dari hasil uji in vitro yang dilakukan (Prabhakaran., et al. 2017), ternyata molukisida nabati yang berasal dari ekstrak tanaman yang perlakuan dikombinasikan memperlihatkan hasil yang lebih baik, pada mortalitas Lc 90 (Nerium indicum Mill., Nicotiana tabacum,L) (Nerium indicum Mill, Nicotina tobacco, Piper ningrum, L), Nerium indicum Mill, Nicotina tabacco, Azadirachta indica, A. Juss. Sedangkan hasil yang dilaporkan oleh (Kurniati, $d k k$., 2015) Lt50 tercapai dengan menggunakan Brotowali tingkat kosentrasi 95000 ppm selama 12,75 jam.

Molukisida nabati tidak saja berguna untuk mengendalikan hama keong mas akan tetapi juga dapat digunakan untuk merangsang pertumbuhan vegetatif tanaman padi (Tabel 3).

Dari tabel 3 terlihat bahwa makin tinggi tingkat kosentrasi molukisida nabati yang diberikan, makin baik pengaruhnya terhadap pertumbuhan vegetatif tanaman padi. Pada perlakuan dengan tingkat kosentrasi $625 \mathrm{ppm}$ memperlihatkan pertumbuhan vegetatif terbaik terutama terhadap tinggi tanaman, jumlah anakan, panjang daun lebar daun, dengan peningkatan pertumbuhan pada perlakuan minyak sirih-sirihan kosentrasi 625 ppm masingmasing $16,90 \%, 52,10 \%, 12,4 \%$ dan $31,2 \%$. Pada perlakuan minyak lemonggras kosentrasi $625 \mathrm{ppm}$ 
peningkatan peertumbuhan lebih rendah dibanding perlakuan minyak siri-sirihan kosentrasi $625 \mathrm{ppm}$ masing-masing $9,49 \%, 31,28 \%, 5,66 \%$ dan $72,72 \%$

Tabel 3. Pertumbuhan vegetatif padi pada umur 4 minggu setelah tanam

\begin{tabular}{lcccc}
\hline \multirow{2}{*}{ Perlakuan } & \multicolumn{4}{c}{ Pertumbuhan Vegetatif } \\
\cline { 2 - 5 } & $\begin{array}{c}\text { Tinggi } \\
\text { Tanaman }(\mathrm{cm})\end{array}$ & $\begin{array}{c}\text { Jumlah } \\
\text { Anakan }(\mathrm{bh})\end{array}$ & $\begin{array}{c}\text { Panjang } \\
\text { Daun }(\mathrm{cm})\end{array}$ & $\begin{array}{c}\text { Lebar } \\
\text { Daun }(\mathrm{cm})\end{array}$ \\
\hline MS 165 ppm & $67,6 \mathrm{~d}$ & $14,9 \mathrm{e}$ & $49,7 \mathrm{c}$ & $1,08 \mathrm{c}$ \\
\hline MS 325 ppm & $71,9 \mathrm{~b}$ & $18,7 \mathrm{c}$ & $50,9 \mathrm{~b}$ & $1,3 \mathrm{bc}$ \\
\hline MS 625 ppm & $77,6 \mathrm{a}$ & $24,8 \mathrm{a}$ & $51,6 \mathrm{a}$ & $1,6 \mathrm{~b}$ \\
\hline ML165 ppm & $59,6 \mathrm{f}$ & $16,6 \mathrm{~d}$ & $40,4 \mathrm{~h}$ & $1,2 \mathrm{bc}$ \\
\hline ML 325 ppm & $68,2 \mathrm{~d}$ & $17,2 \mathrm{~d}$ & $44,8 \mathrm{~g}$ & $1,2 \mathrm{bc}$ \\
\hline ML 625 ppm & $72,7 \mathrm{~b}$ & $21,4 \mathrm{~b}$ & $48,5 \mathrm{~d}$ & $1,9 \mathrm{a}$ \\
\hline MK 625 ppm & $70,6 \mathrm{c}$ & $18,7 \mathrm{c}$ & $47,8 \mathrm{e}$ & $1,1 \mathrm{bc}$ \\
\hline $\begin{array}{l}\text { Kontrol/Tanpa } \\
\text { molukisida }\end{array}$ & $66,4 \mathrm{e}$ & $16,3 \mathrm{~d}$ & $45,9 \mathrm{f}$ & $1,1 \mathrm{bc}$ \\
\hline KK (\%) & 9,13 & 13,78 & 10,97 & 12,34 \\
\hline Kela
\end{tabular}

Keterangan :

- Angka yang diikuti huruf kecil yang tidak berbeda nyata taraf uji 5\% DMNRT.

- Perlakuan keterangannya sama dengan Tabel 1

Hasil ini seirama dengan hasil yang telah dilakukan oleh (Kodir, 2018) dimana pestisida nabati serai wangi dosis 1000 ppm dapat meningkatkan pertumbuhan vegetatif dan produksi padi varitas Inpari 14 di Kabupaten Ogan Komering Ulu Sumsel.

Selain mempengaruhi pertumbuhan vegetatif molukisida nabati juga dapat mempercepat proses generative dari tanaman padi.

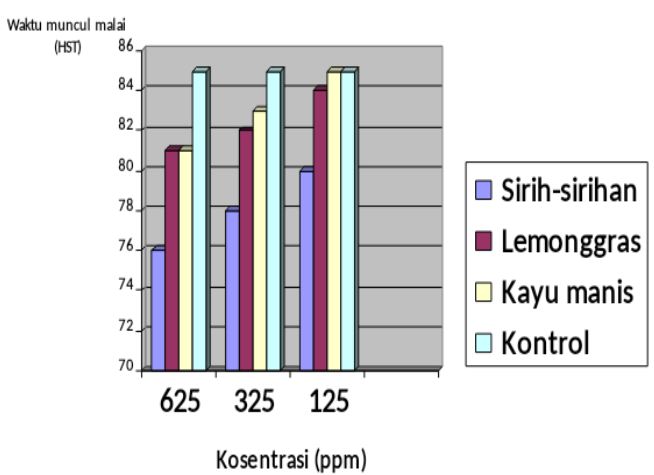

Gambar 2. Saat munculnya malai setelah aplikasi molukisida

Pemberian molukisida nabati dan tingkat kosentrasi mempengaruhi waktu muncul malai, semakin tinggi kosentrasi maka semakin cepat malai muncul, ini diasumsikan bahwa pemberian molukisida dapat merangsang pertumbuhan malai tanaman padi.

\section{SIMPULAN}

Dari hasil penelitian dapat disimpulkan bahwa pestisida nabati minyak sirih sirihan dan lemonggras pada semua kosentrasi yang dipakai dapat bersifat sebagai molukisidal terhadap Keong mas, memberikan pertumbuhan vegetatif terbaik serta mempercepat masa generatif terhadap tanaman padi. Selain itu dapat meningkatkan nilai ekonomis dari tanaman liar sirih-sirihan..

\section{DAFTAR PUSTAKA}

Bunga, J.A., F.X. Wagiman., Witjaksono dan JHP. Sidadolog. 2016. Daya Makan, Diapause dan Mobilitas Keong Mas (Pomacea canaliculata) pada berbagai Kedalaman Air. J. HPT Tropika 16 (2):147-154.

Cicció, José F. y Cynthia M. Ballestero.1997. Constituyentes 
volátiles de las hojas y espigas de Piper aduncum (Piperaceae) de Costa Rica. Rev.Bio.Trop 45 (2): 783-790.

Dadang dan Prijono, 2008. Insektisida nabati prinsip, pemanfaatan dan pengembangan. Departemen Proteksi Tanaman. Fakultas Pertanian. IPB. $163 \mathrm{hlm}$

Direktorat Perlindungan Tanaman Pangan. 2008. Luas Serangan Siput Murbai pada Tanaman Padi Tahun 1997-2006, Rerata 10 tahun dan tahun 2007. Direktorat Jenderal Tanaman Pangan. Jakarta

Idris. H dan Nurmansyah. 2018. The Potential of essential oil botanical molluscicide for controlling GAS. Laporan hasil penelitian $.10 \mathrm{hlm}$.

Jamal, Y., A Agusta dan Praptiwi. 2003. Komposisi Kimia dan Efek Antibakteri Minyak Atsiri Buah Gedebong (Piper aduncum L.). Majalah Farmasi Indonesia 14(1):284-289.

Kodir. K.A. 2018. Pertumbuhan dan Hasil Padi Sawah INPARI 14. Prosiding Seminar Nasional Membangun Pertanian Modern dan Inovatif Berkelanjutan dalam Rangka Mendukung MEA. Hlm 326-333.

Kurniawati. D., R Rustam., dan J.H. Laoh. 2015. Pemberian Beberapa Konsentrasi Ekstrak Brotowali (Tinospoacrispa L.) untuk Mengendalikan Keong Mas (Pomacea sp.) pada Tanaman Padi (Oryza sativa, L.). JOM Faperta 2(1): $8 \mathrm{hlm}$.

Mauludi, L dan A. Asman. 2004. Perkembangan hasil penelitian Teknologi Produksi minyak atsiri Indonesia. Prosiding Seminar Ekspose Teknologi Gambir dan , Kayu manis dan Atsiri Laing Solok 2 Desember 2004.Hlm 38-47.

Min. W and X. Yan. 2006. The golden applesnail (Pomacea canaliculata) in China. Joshi RC\& Sebastian LS (eds). Global advences in ecologyand management of golden apple snail. Phil Rice, Ingeneria. P285-289
Mwonga, K.B., N.E. Waniki., Y.L. Dorcas., and N.M. Piero. 2016. Molluscicidal Effects of Aqueous Extracts of Selected Medicinal Plants from Makueni County, Kenya . Pharmaceutica

Nurmansyah. 2012. Minyak Atsiri Piper aduncum sebagai Bahan Baku Pestisida Nabati untuk Pengendalian Jamur Penyakit Tanaman. Bunga Rampai Inovasi Tanaman Atsiri Indonesia . Badan Penelitian dan Pengembangan Pertanian hlm 178186.

Prabhakaran G., S.J Bhore and M Ravichandran. 2017. Development and Evaluation of Poly Herbal Molluscicidal Extracts for Control of Apple Snail (Pomacea maculata). Agriculture $\quad 7(22)$ : 1-11; doi:10.3390/agriculture7030022 www.mdpi.com/journal/agriculture

Prijono D. 2005. Pengembangan dan Pemanfaatan Insektisida Botani. Departemen Proteksi Tanaman Fakultas Pertanian . Institut Pertanian Bogor.

Shoaib M.A., M.F. Mahmoud., N Loutfy., M.A. TawWc, and M Barta. 2010. EVect of botanical insecticide Nimbecidine ${ }^{\circledR}$ on food consumption and egg hatchability of the terrestrial snail Monacha obstructa. J Pest Sci 83:27-32. DOI 0.1007/s10340-0090265-x

Sudrajat, D. Susanto, dan D Mintargo. 2011.Bioekologi dan Potensi Senyawa Bioaktif Sirih Hutan (Piper aduncum L) sebagai sumber Bahan baku Larvasida Nyamuk Aedes aegypty L. Mulawarman Scientifie 10 (1): 63-74.

Yunidawati. W., D Bakti, dan BSJ. Damanik. 2011. Penggunaan Ekstrak Biji Pinang untuk Mengendalikan Hama Keong Mas (Pomacea canaliculata Lamarck) pada Tanaman Padi. Jurnal Ilmu Pertanian Kultivar 5(2): 83-90. 
Jurnal Agrosains dan Teknologi Volume 5 Nomor 2 Desember 2020 website : jurnal.umj.ac.id/index.php/ftan
p-ISSN 2528-020 1

e-ISSN 2528-3278 